\title{
A onda quebrada - evangélicos e conservadorismo*
}

\author{
Ronaldo de Almeida**
}

\section{Resumo}

Este artigo pretende compreender a conjuntura político-religiosa contemporânea no Brasil com um duplo enfoque: por um lado, na atuação e nos valores políticos dos evangélicos mais visíveis na cena nacional e, por outro, no conservadorismo crescente no país. $\mathrm{O}$ argumento é que parcela desses religiosos está articulada a linhas de força em diferentes dimensões (econômica, moral, securitária $e$ interacional) do processo social em curso no país $e$ que configuram o que tem sido denominado com relativa imprecisão de "onda conservadora".

Palavras-chave: Evangélicos, Conservadorismo, Religião, Política, Bancada Evangélica.

* Recebido para publicação em 5 de maio de 2017, aceito em 16 de maio de 2017.

** Professor do Departamento de Antropologia da Universidade Estadual de Campinas, Campinas-SP, e pesquisador do Cebrap, São Paulo, Brasil. ronaldormalmeida@gmail.com 
The Broken Wave: Evangelicals and Conservantism

\begin{abstract}
:
This article aims to understand the contemporary political-religious conjunture in Brazil focusing on two fronts: on one hand, the performance and political values of the most prominent evangelicals on the national scene and, on the other hand, on the growing conservantism in the country. The argument is that a segment of these religious groups is articulated along lines of force in different dimensions (economic, moral, security and interactional) of the social process in progress in the country, and that they configure what has been denominated with relative imprecision as a "conservative wave".
\end{abstract}

Keywords: Evangelicals, Conservantism, Religion, Politics, Evangelical Bloc. 


\section{Introdução}

O Brasil vem passando nos últimos anos por processos políticos que têm levado a perdas de determinadas conquistas no universo dos direitos construído, principalmente, após a redemocratização. Consolidaram-se nos últimos anos forças que trabalham a favor da contenção, da restrição e do retrocesso de alguns direitos garantidos com a promulgação da Constituição de 1988. Tal movimento tem sido denominado de "onda conservadora".

Primeiramente, contudo, cabe uma questão metodológica. Como definir conservadorismo ou pauta conservadora? Enfim, conservador em relação a quê e em qual plano de comparação? Por exemplo, é recorrente em pesquisas de opinião pública a pergunta sobre pena de morte ser um dos indicadores de conservadorismo. No entanto, a questão não é boa para tipificar os evangélicos brasileiros, pois na quase totalidade são contrários a ela. Pena de morte, aborto e eutanásia, cada um com suas justificações teológicas específicas, guardam em comum a condenação à violação da vida dada por deus, e só a ele cabe encerrá-la. Outro exemplo: há pessoas portadoras de deficiência física que militam pela ampliação das pesquisas genéticas (tema ético controverso), mas podem ser contrárias à descriminalização do aborto porque elas mesmas poderiam ter sido abortadas. Ou, ainda, uma das referências da grande mídia em temas da conjuntura cultural e política do país, escreveu recentemente que suas preferências ideológicas são os pensadores liberais britânicos e concluiu afirmando não ter nada em comum com o pastor pentecostal Silas Malafaia, muito embora ambos tenham sido colocados do mesmo lado no debate público sob a pecha de "de direita".

Butler (2015), em Quadros de Guerra, desenvolve o argumento (que é tanto teórico quanto metodológico, embora não enunciado desta forma) de que os conflitos político-culturais que opõem os islâmicos aos gays, ou a moral religiosa à diversidade de gênero, devem ser compreendidos a partir dos 
"enquadramentos" que produzem polarizações e naturalizam as identidades. Para Butler, o enquadramento de guerra reduz a diversidade interna entre os polos antagonizando as posições políticas. Como corolário, nos contextos políticos liberais $e$ multiculturais, as pautas de LGBT são valorizadas em detrimento de posturas religiosas repressivas como a de alguns islâmicos.

$\mathrm{Na}$ conjuntura brasileira atual, a situação política é de persistente e reificada polarização. Conservadorismo não é algo contrário às normas democráticas, entretanto, no enquadramento do debate público há uma sobreposição - por vezes, excessiva $e$ imprecisa - na identificação de conservadores, fascistas $e$ fundamentalistas. Ciente disso, não parto propriamente de definições a priori desses termos nem da autodeclaração daqueles que se nomeiam como tais. Considero-as como categorias construídas relacionalmente no embate político, que está significativamente pautado pelos meios de comunicação mais hegemônicos. Mais especificamente, trata-se de categorias políticas de acusação que circunscrevem um conjunto relativamente variado de discursos, valores, ações e posicionamentos políticos com interesses parciais e conjunturalmente comuns.

Ressalte-se que, cada vez mais, tais identificações, sobretudo "de direita", vêm sendo assumidas publicamente sem os constrangimentos do período inicial da redemocratização do país. Ao contrário, atualmente o estigma recai sobre quem se autodeclara "de esquerda". O termo progressista não está tão negativado, ainda.

Fundamentalismo, por sua vez, é um termo de acusação contra "os evangélicos", frequente nos meios de comunicação $e$ presente, principalmente, nas redes sociais. É incomum evangélicos brasileiros identificarem-se como fundamentalistas; o que não se passa nos EUA, onde é possível encontrar de maneira expressiva essa autodeclaração. No Brasil, os sentidos para os quais o termo remete têm como referência, em boa medida, o temor do terrorismo islâmico e a preocupação com o moralismo do protestantismo norte-americano, que é o berço teológico e eclesial dos evangélicos brasileiros. 
A mesma cautela com as categorias descritivas também deve ser utilizada na compreensão de "os evangélicos". O que ela circunscreve? Evangélicos (sobretudo, pentecostais) fazem parte da onda, mas não somente eles. Também não se trata da totalidade deles, mas de uma parcela significativa que encontrou, até o momento, poucos contrapontos internos expressivos. É necessário, portanto, ressaltar que a categoria englobante "os evangélicos" foi algo que se consolidou nas últimas décadas. Há certo tempo, era também comum e mais equitativo o uso das nomeações "crentes" ou "protestantes" (que incluíam os pentecostais) para circunscrever esse segmento religioso em crescimento. Em parte, a categoria descritiva "evangélicos" foi estabilizada de forma técnico-científica. ${ }^{1}$ Mas também alguns sentidos reverberados, principalmente, pelos meios de comunicação foram associados a eles, cuja imagem bastante difundida no Brasil sintetizei da seguinte maneira:

um segmento religioso formado por pessoas na maioria das vezes honestas e confiáveis nas relações face a face, mas pouco tolerantes com religiões e morais alheias, e cujas lideranças costumam ser percebidas com desconfiança, sendo algumas consideradas ambiciosas e arrivistas (Almeida, 2007:174).

Também criminosas, acrescento, hoje. Eduardo Cunha, da Assembleia de Deus, e o (ex) Bispo Rodrigues, da Igreja Universal, testemunham a favor dessa percepção. ${ }^{2}$

\footnotetext{
1 Refiro-me à classificação do Censo Demográfico que estabeleceu dois grandes grupos nos quais as diferentes denominações são alinhadas: evangélicos pentecostais e evangélicos não pentecostais. Da mesma forma, a literatura das ciências sociais da religião, mesmo marcando as diferenças internas, valeu-se da categoria evangélicos na análise do campo das religiões no Brasil (Fernandes et alli, 1998; Mafra, 2001; Freston, 2004; Fonseca, 2008; Almeida, 2009; Oro; Alves, 2016).

2 O primeiro está sendo incriminado no caso nomeado "Petrolão" e o segundo o foi no "Mensalão".
} 
Entretanto, tal definição não compreende a diversidade dos que se autodeclaram evangélicos, tanto de fiéis como de lideranças religiosas e políticas. Muitos destes destoam do mainstream conservador (cuja atuação política dá-se mais pela via eleitoral) e preferem a militância política mais na esfera da sociedade civil (movimentos, associações, ONG, terceiro setor etc.) com posicionamentos mais progressistas. Na verdade, evangélico, mais do que em qualquer outro momento de sua história no Brasil, é um termo em acirrada disputa entre os que se autodeclaram dessa forma. Devido a alguns estigmas adquiridos pela categoria nos últimos anos, muitos protestantes históricos $e$ pentecostais têm preferido identificar-se pelo nome específico de sua denominação e pelo termo genérico "cristão".

Isso posto, o procedimento metodológico é identificar para onde aponta o termo de acusação conservador, que será apreendido a partir do próprio debate público. A quem e a quê se refere? Da mesma forma, a quem e o quê se refere o termo "os evangélicos"? Em síntese, a pergunta mais precisa para os objetivos deste artigo é como alguns evangélicos (a parcela hegemônica e com visibilidade) adensam o que tem sido denominado "onda conservadora" sendo constituintes $e$ constituídos por ela?

\section{Bancada Evangélica: composição e atuação}

Bancada Evangélica talvez seja a expressão mais acabada do sentido negativo que o termo "os evangélicos" adquiriu nas últimas décadas, qual seja: um conjunto de deputados "moralistas" que ameaçam a laicidade do Estado brasileiro. $\mathrm{Na}$ verdade, essa ameaça pressupõe, enganosamente, que já temos um Estado em que as religióes pouco influenciam as questões de ordem pública. Essa percepção é possível porque o catolicismo e a Igreja Católica gozam de relativa invisibilidade no espaço público por sua profundidade histórica, cultural e jurídica no país. Invisibilidade no sentido de desfrutar, mais do que qualquer outra religião, de legitimidade e oficialidade que a naturalizam na 
paisagem social brasileira, conforme o conceito de igreja (oposto à seita), formulada por Ernest Troeltsch (1987), segundo o qual trata-se de uma instituição extensiva à ordem social como, por exemplo, na esperada sobreposição entre ser brasileiro e ser católico. Isso, no entanto, é cada vez menos verdadeiro devido ao crescimento do pluralismo religioso concorrencial no país, que torna as digitais da instituição católica mais visíveis.

A presença das religióes nos poderes da República são expressões de alguns deslocamentos na estrutura social brasileira. Os evangélicos ascenderam demograficamente e produziram seus canais políticos no Legislativo e no Executivo, mas em menor incidência no Judiciário. Eles têm demonstrado forte capacidade de indução do voto, mais do que qualquer outra religião no país. Se voto é confiança, o vínculo religioso entre candidato e eleitor a atesta. Isso não significa que eles só votem nos "irmãos de fé", mas o vínculo é expressivo tanto na eleição proporcional como na majoritária (Machado, 2006; Mariano, 2016). Assim, a via eleitoral permitiu acesso às elites políticas de religiosos com menos capitais econômico, cultural e social do que o necessário para a mobilidade no Poder Judiciário, cujo perfil é predominantemente elitizado, tradicional e católico. Como corolário, para compreender por onde passam os interesses católicos no Estado, uma ampliação empírica é necessária: o Judiciário deve ser também um dos focos centrais.

Mas como o objetivo deste artigo é compreender a relação entre conservadorismo e evangélicos na conjuntura atual, restrinjo-me a estes religiosos e os circunscrevo no sistema político tendo como locus central de atuação a Câmara dos Deputados. 
Tabela 1 - Partidos x Deputados evangélicos em 2015

\begin{tabular}{|l|c|c|}
\hline Partidos & Deputados Evangélicos & Total de Deputados \\
\hline PSDB & 5 & 54 \\
\hline PMDB & 5 & 66 \\
\hline PT & 2 & 70 \\
\hline Subtotal & 12 & 190 \\
\hline & & 22 \\
\hline DEM & 3 & 25 \\
\hline PTB & 3 & 34 \\
\hline PSB & 2 & 19 \\
\hline PDT & 2 & 10 \\
\hline PPS & 1 & 110 \\
\hline Subtotal & 11 & 21 \\
\hline & 17 & 12 \\
\hline PRB & 8 & 34 \\
\hline PSC & 6 & 15 \\
\hline PR & 6 & 36 \\
\hline SD & 4 & 37 \\
\hline PP & 4 & 5 \\
\hline PSD & 1 & 3 \\
\hline PHS & 1 & 11 \\
\hline PMN & 1 & 4 \\
\hline PROS & 1 & 178 \\
\hline PTN & 49 & \\
\hline Subtotal & & \\
\hline
\end{tabular}

Fonte: site da Câmara dos Deputados. http://www2.camara.leg.br/

A Tabela 1 mostra o padrão da presença evangélica na Câmara dos Deputados. Ao total, são 72 deputados em 18 partidos, que foram agrupados segundo tamanho, tempo de existência ou expressão política nacional. Os maiores partidos, agrupados em cor verde, possuem 190 dos deputados do universo total de 536, mas têm apenas 12 declarados evangélicos. Partidos médios e tradicionais, em azul, têm 11 entre 110 deputados. A cor vermelha cobre partidos pequenos ou com pouca expressão política. Cerca da metade deles foi fundada no período petista no governo federal. A maior parte dos deputados evangélicos, 49, encontra-se nesses partidos do chamado "baixo clero", que costumam ter forte influência da mesa da Câmara, como teve a presidência do ex-deputado Eduardo Cunha, pelo menos até a consolidação do impeachment de Dilma Rousseff, em 17 de abril 
de 2015 (Limongi, 2015). Além da importância do PMDB, a liderança de Cunha entre muitos deputados evangélicos deveu-se, principalmente, ao seu vínculo religioso com a Igreja Assembleia de Deus Convenção Madureira.

Dos 72 deputados evangélicos, cerca de um quinto pertence ao evangelismo não pentecostal enquanto quatro quintos pertencem ao evangelismo pentecostal. ${ }^{3}$ Entre as 14 denominações com deputados federais, as pentecostais Assembleia de Deus e a Igreja Universal do Reino de Deus têm 36.

\section{Tabela 2 - Denominação por partido em 2015}

\begin{tabular}{|l|c|c|}
\hline Partidos/Denominação & Assembleia de Deus & Igreja Universal \\
\hline PSC & 6 & \\
\hline PR & 3 & \\
\hline PRB & 3 & 11 \\
\hline PSD & 2 & \\
\hline PSDB & 2 & \\
\hline PTB & 2 & \\
\hline PROS & 1 & \\
\hline PSB & 1 & \\
\hline SD & 1 & \\
\hline PDT & 1 & \\
\hline PHS & 1 & \\
\hline PMDB & 1 & 11 \\
\hline PPS & 1 & \\
\hline Total & 25 & \\
\hline
\end{tabular}

Fonte: site da Câmara dos Deputados. http://www2.camara.leg.br/

325 deputados da Assembleia de Deus, 11 da Igreja Universal do Reino de Deus, 7 Batista, 5 Presbiteriana, 4 Evangelho Quadrangular, 4 da Mundial do Reino de Deus, 3 da Internacional da Graça de Deus, 2 Congregação Cristã do Brasil, 2 Metodista, 1 Luterana, 1 Renascer em Cristo, 1 Sara Nossa Terra, 1 Comunidade Cristã Nova, 1 Evangelho Eterno, Fonte da Vida, Cristã Maranata, Projeto Nova Vida, Evangélico não identificado. 
Nas últimas décadas, a Assembleia de Deus fragmentou-se institucionalmente sem abrir mão da doutrina e da identidade "assembleianas". Como consequência, esse universo é composto por grandes convenções e pulverizado em pequenos ministérios que se diferenciam por questões doutrinárias pontuais, muitas disputas políticas e, por fim, pelo acréscimo de um termo ao nome da igreja (Freston, 1994; Alencar, 2013; Correa, 2012). ${ }^{4}$ A descentralização institucional das Assembleias de Deus refletiu-se também, mas não só por causa dela, na vinculação a diferentes partidos políticos. A institucionalidade da Igreja Universal do Reino de Deus, por sua vez, é mais centralizada dos pontos de vista doutrinário, ritualístico, administrativo, financeiro e também partidário. Todos estão no $\mathrm{PRB}$, que ainda conta com 12 deputados não evangélicos.

A partir de um conjunto de temas em torno dos quais os parlamentares evangélicos têm atuado, foi possível classificar 178 proposições, conforme o Gráfico 1. Essas proposições são alguns indicativos dos focos da atuação parlamentar evangélica com vista à legitimação no meio religioso e, consequentemente, à aprovação de seus eleitores. Nem todos os temas podem ser classificados conservadores. Por exemplo, muitas das proposições relativas às mulheres dizem respeito à saúde, às condições de trabalho ou à violência doméstica. Mas, em relação aos direitos reprodutivos $e$ sexuais e à família, a moral religiosa é um orientador significativo da atuação dos deputados.

${ }^{4}$ Cito algumas: Assembleia de Deus Vitória em Cristo, Assembleia de Deus dos Últimos Dias, Assembleia de Deus Bereana, Assembleia de Deus 25 de agosto, Assembleia de Deus Família, Assembleia de Deus Mananciais de Vida, Assembleia de Deus Pentecostal Garagem de Fogo, Assembleia de Deus Ministério Vivendo a Arca, Assembleia de Deus Missionária, entre outras. Nesse sentido, cada vez mais a Assembleia de Deus torna-se tão diversa quanto o próprio meio pentecostal. 
Gráfico 1 - Tipo e quantidade das proposições em 2015

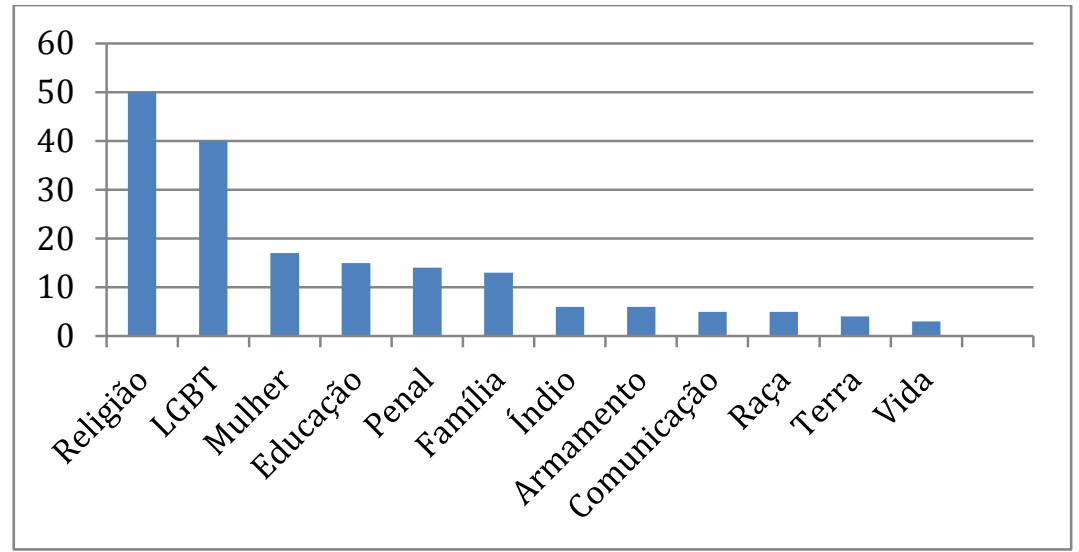

Fonte: site da Câmara dos Deputados. http://www2.camara.leg.br/

O Gráfico 2, abaixo, mostra a centralidade das Assembleias de Deus e da Igreja Universal no número de proposições durante o ano de 2015. Apesar da fragmentação partidária das Assembleias de Deus, elas realizam uma atuação mais uniforme, por um lado, em temas religiosos e de ordem moral e, por outro, em interesses mais gerais que são articulados em torno da Frente Parlamentar Evangélica. Mas, diferente da Assembleia de Deus, a Igreja Universal é menos propositiva em questões morais, embora acompanhe nas votações os posicionamentos mais conservadores. 


\section{Gráfico 2 - Número de proposições por denominação}

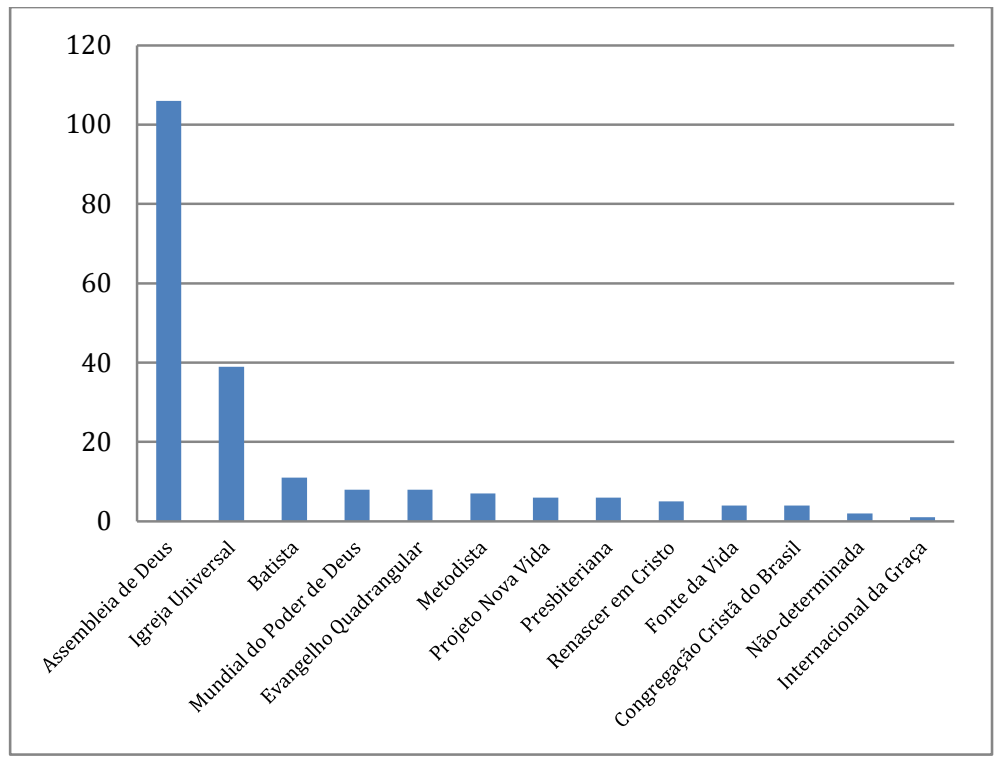

Fonte: site da Câmara dos Deputados. http://www2.camara.leg.br/

O perfil de muitos políticos evangélicos, obedecendo a lógica das candidaturas proporcionais, acentua posições que os identificam com o segmento religioso, mas isso cria dificuldades quando as eleições são majoritárias, uma vez que estas implicam em ampliação do discurso político. Entretanto, diferente da visão mais estereotipada dos evangélicos como afirmado anteriormente, os fieis são mais tolerantes e menos rigorosos no plano das relações interpessoais do que aparentam os que dizem representálos no sistema político. Aborto e homossexualidade entre pessoas próximas são mais transigidos na vida cotidiana do que defendidos no espaço público (compreendido como visibilidade legítima e ordenamento jurídico). Isso não é propriamente uma característica tão somente dos evangélicos, mas diz respeito ao conservadorismo da própria sociedade brasileira, que lida de forma mais flexível nas relações interpessoais e com maior rigidez de valores morais no espaço público. 
Acrescente-se, ainda, que os deputados não são apenas evangélicos ou tão somente representam esses interesses. Uma parcela dos deputados saiu dos quadros das Igrejas, mas outros tiveram diferentes trajetórias profissionais (empresários, advogados, policiais) e econômicas, o que os coloca em órbitas de influências políticas variadas. Como membros do Parlamento, sua atuação tem outras facetas e vetores. Da mesma forma, a denominada "onda conservadora" não deve ser compreendida como uniforme, mas trata-se de uma vaga que quebra em várias direções, e qualquer tentativa de leitura demasiadamente totalizante perderá boa parte da diversidade do processo social. As direções estão articuladas em conexões parciais em torno de uma concertação mais ampla.

Nesse sentido, proponho compreender a conjuntura político-religiosa no Brasil atual como composta por linhas de força que cooperam para a resultante que tem sido considerada conservadora. Elas não se sobrepõem completamente, podendo até serem contraditórias em pontos específicos, mas articulam-se em torno de opositores comuns. Quatro linhas de força parecemme centrais para compreender a conjuntura atual e a participação evangélica no que tem sido nomeado como "onda conservadora", a saber: econômica, moral, securitária e interacional.

\section{Meritocrática e empreendedora}

No vetor econômico, o enquadramento do debate público aponta para posições que celebram o esforço e o mérito individuais, e opõe-se, por exemplo, a políticas públicas e sociais de transferência de renda, como o Programa Bolsa Família dos governos Lula e Dilma. Tal política redistributiva, assim como outras, é percebida como clientelismo político e forma de acomodação dos pobres para o trabalho. As manifestações de 15 de março de 2015, a primeira convocada contra o governo Dilma, ocorreram em uma forte conjuntura de perda de legitimidade da Presidente da República em função do questionamento de sua reeleição e da gestão econômica. Esse evento - principalmente em 
relação ao que ocorreu na Av. Paulista, em São Paulo, e em Copacabana, no Rio de Janeiro - foi acusado de elitista e de reafirmar distinções sociais por ser contrário às políticas redistributivas dos governos petistas. $\mathrm{O}$ sentido do discurso foi de menos Estado na distribuição de benefícios e mais empreendimento individual. ${ }^{5}$

$\mathrm{O}$ mérito decorrente do esforço próprio é valorizado $e$ incentivado religiosamente. Essa é uma característica do discurso neopentecostal que se dissemina cada vez mais pelo pentecostalismo clássico, principalmente pela Assembleia de Deus. Não se trata da ética protestante classicamente analisada por Weber, em que o lucro decorre de uma conduta econômica metódica e cuja ética confere valor religioso a quem é bemsucedido no trabalho secular; e muito menos de uma ética da providência, como no pentecostalismo clássico das camadas mais populares, segundo a qual deus provê aqueles que permanecem fiéis a ele nos momentos de necessidades materiais, as quais nunca deixam de surgir.

A Teologia da Prosperidade neopentecostal, por sua vez, prega uma ética econômica voltada para o mundo, onde possuir $e$ ascender são sinais de que Deus, e não o diabo, age em sua vida. Essa ascensão não se ancora especificamente na disciplina $e$ na dedicação ao trabalho, mas em uma disposição empreendedora de quem almeja tornar-se o patrão nas relações de trabalho. Tal disposição de empreender é alimentada por ritos sacrificiais como dar o dízimo - que geram expectativas de prosperidade material no futuro. Os riscos materiais do empreendimento são considerados atos de fé.

Mas nem só de rito alimenta-se a Teologia da Prosperidade. A Igreja Universal oferece cursos para empresários empreendedores. Trata-se de orientações contábeis, de legislação,

\footnotetext{
5 Na disputa simbólica da conjuntura política incerta porquê passa o país, os termos de acusação se multiplicam em planos distintos. No plano do escracho, o segmento acusado de elitista foi denominado como "coxinhas", que, por sua vez, acusa o PT (e a esquerda) de "petralhas".
} 
planejamento econômico etc, funcionando como uma espécie de incubadora de pequenas empresas comerciais (Gutierrez, 2017).

Em linhas gerais, a Teologia da Prosperidade tem uma afinidade de sentido com a informalidade $e$ a precariedade do trabalho, como as que ocorreram no Brasil nos anos de recessão econômica nos anos 1980 e 1990, e também com os momentos de aumento de consumo, como nos anos 2000. Em ambas as situações, a doutrina religiosa é capaz de gerar disposições empreendedoras de caráter individualista. $\mathrm{O}$ mérito decorre do esforço ativo e da atitude empreendedora, e não propriamente do capital social e de suas distinções sociais. Isso não significa que os evangélicos não usufruam dos programas sociais do governo federal, mas o discurso da prosperidade material, resultante de sacrifícios rituais monetários e de atitude empreendedora, é valorizado religiosamente e adotado como ética econômica. ${ }^{6}$

Em sintonia com a percepção popular de crise econômica, o empreendedorismo foi um dos principais temas centrais da campanha de Marcelo Crivella para prefeito do Rio de Janeiro, como a proposta de isenção de impostos para empreendimentos econômicos em regióes de favela, quase sempre de iniciativas locais. Nos programas de TV, o tema era tratado pelo candidato em conversa com jovens, homens e mulheres, predominantemente negros. O marketing de Crivella marcou distância da Universal, sem, contudo, perder o seu eleitorado. No programa de TV, centrado no discurso do Estado mínimo, enfatizou o empreendedorismo sem falar de religião, enquanto nas igrejas pregava-se o empreendedorismo sem fazer referência à política.

Se no nível individual o discurso religioso procura gerar disposição para o empreendedorismo, no plano da política institucional, muitos agentes políticos evangélicos militam declaradamente por uma agenda liberal. $\mathrm{Na}$ campanha

${ }^{6}$ É recorrente em pesquisas qualitativas de opinião pública os entrevistados atribuírem a si ou a deus o sucesso na vida $e$ ao governo as dificuldades da mesma. 
presidencial de 2014, o candidato Pastor Everaldo, com 0,75\% dos votos, fez o discurso que combina menor presença do Estado na economia e mais regulação jurídica da moralidade pública. $\mathrm{O}$ então presidente da Câmara dos Deputados, Eduardo Cunha, foi protagonista na aprovação, em primeira instância, do Projeto das Terceirizações ${ }^{7}$, que contou com o voto da Frente Parlamentar Evangélica. Ou, ainda, vale citar a disputa do PSC pela FUNAI, órgão federal central no processo de demarcação de terras indígenas e quilombolas. Na CPI da FUNAI-INCRA ${ }^{8}$, na Câmara dos Deputados, a Frente Parlamentar Evangélica operou como linha auxiliar da denominada bancada do agronegócio e da mineração em oposição aos que militam pelos direitos dos indígenas, sobretudo, à terra. Interessa à Frente Evangélica abrir espaço para ação missionária evangélica entre os indígenas como forma de legitimação interna dos políticos religiosos. Terras $e$ almas são bens em disputa que articulam diferentes atores do Congresso Nacional.

Para concluir, é necessário situar a questão econômica em relação a outro ator político de maior envergadura: Marina Silva, candidata à presidência em 2010 e 2014. No que diz respeito aos temas sociais e econômicos, sua imagem pública foi construída em torno dos referenciais da esquerda petista e do ambientalismo; $e$, religiosamente, destacam-se as referências católicas ligadas aos movimentos sociais (seringueiros e CEBs). Seu período de formação política foi em meio a uma forte influência dos setores progressistas da Igreja Católica. A conversão à Igreja Evangélica Assembleia de Deus deu-se nos anos 1990, e até o momento ela demonstra não ter adotado a Teologia da Prosperidade como ética econômica religiosa. Apesar dessa imagem pública consolidada, na última campanha presidencial, em 2014, Marina construiu seu plano econômico de governo em uma agenda considerada mais próxima da orientação econômica neoliberal,

\footnotetext{
7 PL 4302/1998.

8 http://www2.camara.leg.br/atividade-legislativa/comissoes/comissoestemporarias/parlamentar-de-inquerito/55a-legislatura/cpi-funai-e-incra.
} 
como a proposição de autonomia do Banco Central, o que a aproximou do eleitorado do PSDB.

\section{Moralmente reguladora}

Outra linha de força refere-se à disputa pela moralidade pública, que no Brasil encontra nas religiões cristãs os principais canais de sacralização da família e da reprodução da vida. $\mathrm{Na}$ atualidade, a Igreja Católica mantém suas posições ortodoxas nesses temas, embora o Papa Francisco venha dando sinalizações em direção ao acolhimento de divorciados, mães solteiras, gays, entre outros. Suas sinalizações têm como objetivo o acolhimento pastoral a fim de não perder os fiéis mais do que promover mudanças profundas nos dogmas (Almeida, 2013). Mas a resultante desses vetores internos ao catolicismo é a Igreja Católica ainda ser um forte ator de contenção em temas como pesquisas genéticas, aborto, casamento e adoção de crianças por casais homossexuais.

Entretanto, os protagonistas mais visibilizados do conservadorismo moral religioso nos últimos anos têm sido os evangélicos pentecostais que entraram, mais do que em qualquer outro momento, na disputa pela moralidade pública para maior controle dos corpos, dos comportamentos e dos vínculos primários. Flávio Pierucci (1987) já havia anunciado que o crescimento evangélico nas eleições para a Assembleia Nacional Constituinte, em 1986, apontava para o fortalecimento do conservadorismo religioso e político no país. Cabe dizer, que o país viveu, entre idas e vindas, no período democrático recente alguns avanços na conquista de direitos (civis, sociais, reprodutivos, sexuais etc). Os discursos mais frequentes dos religiosos mais conservadores (católicos e evangélicos) são de que se faz necessária a contenção dos avanços do secularismo nos comportamentos e nos valores.

Com força política, econômica e demográfica, as pautas de ordem moral têm sido canalizadas de forma mais contundente no Poder Legislativo - algo relativamente recente. A entrada dos evangélicos na política institucional nos anos 1980 visou mais à 
canalização de recursos para a rede religiosa (isenção de impostos e concessões de meios de comunicação) do que uma ação contundente no sentido de maior regulação dos comportamentos (sexuais e reprodutivos), dos corpos (transgênero e pesquisas genéticas) e dos vínculos primários (casamento e adoção gays). Mas, desde 2013, após negociação entre o Governo Dilma e o PSC, a Comissão de Direitos Humanos e Cidadania da Câmara dos Deputados (CDHC) - historicamente associada a temas relativos às questões indígenas, agrárias, imigratórias, de violência no campo e na cidade etc. - tem sido um dos palcos da ação de religiões cristãs com o intuito de regular e restringir a moralidade liberal e laica.

As proposições de ordem moral não apontam somente para um tradicionalismo que apenas resiste ao mundo em mudança, como comportam-se setores da Igreja Católica. Os evangélicos pentecostais têm um conservadorismo ativo e não apenas reativo destinado à manutenção do status quo tradicional de caráter mais católico. A esses evangélicos têm interessado a disputa pela moralidade pública (Casanova, 1994). Não somente a proteção da moralidade deles, mas a luta para ela ser inscrita na ordem legal do país.

Assembleia de Deus, em suas subdivisões, tem sido protagonista em levantar algumas bandeiras. ${ }^{9}$ Três projetos são emblemáticos. O primeiro é o Estatuto do Nascituro ${ }^{10}$, o qual propõe estender os direitos do Estatuto da Criança e do Adolescente (ECA) ao feto, a começar pelo direito à vida. $\mathrm{O}$ segundo é o Estatuto da Família ${ }^{11}$, que a define como constituída tão somente a partir da união de um homem com uma mulher.

\footnotetext{
9 Três figuras se destacaram: o ex-presidente da Câmara dos Deputados, Eduardo Cunha, da Assembleia de Deus Madureira; o deputado federal pastor Marcos Feliciano, da Assembleia de Deus do Avivamento; e o pastor Silas Malafaia, da Assembleia de Deus Vitória em Cristo.

${ }^{10}$ PL 478/2007.

${ }^{11}$ PL 6583/2013.
} 
Por fim, o apelidado "projeto de Cura Gay"12, que suspende o trecho da resolução do Conselho Federal de Psicologia de 1999 que proíbe o tratamento e a cura de homossexualidade, além de vetar manifestações preconceituosas em relação aos homossexuais. A despeito dos projetos serem ou não aprovados, o importante é seu efeito catalizador e canalizador que tem resultados concretos nas eleições proporcionais. ${ }^{13}$

Mas não é possível generalizar os evangélicos pentecostais a partir dessas posições. Quando se intensificou no país o debate público (na verdade, mais restrito às camadas escolarizadas) em torno das pesquisas com células-tronco embrionárias $e$, a reboque naquele momento, o da legalização do aborto, a Igreja Universal declarou-se a favor das pesquisas ${ }^{14}$ e admitiu o aborto nos casos já definidos pela legislação brasileira (estupro, perigo de vida para a mãe e feto com anencefalia). ${ }^{15}$ Tais posições foram uma forma da Igreja Universal se colocar na discussão em contraposição à Igreja Católica. Mais recentemente, o bispo Macedo tem feito pregações no sentido de que não cabe às igrejas evangélicas atuarem para que o Estado estabeleça proibições em questões consideradas religiosas. O Estado não deve ser instado a tratar desses temas, mais especificamente: o ensino religioso, a homoafetividade, o aborto $e$ as pesquisas com células-tronco embrionárias. Para concluir, os deputados do PRB ligado à Igreja Universal fizeram pouquíssimas proposições na $\mathrm{CDHC}$ presidida pelo deputado

\footnotetext{
${ }^{12}$ PL 4931/2016.

${ }^{13}$ A eleição de Crivella para um cargo majoritário, na verdade, pode ser considerada a primeira de um candidato cuja base política inicial foi o meio evangélico. Ele conseguiu ultrapassar significativamente o eleitoral evangélico $e$ mesmo o religioso. Sua identificação foi com o conservadorismo moral do espaço público no Brasil.

${ }^{14}$ Além dela, manifestaram-se também a favor setores mais liberais do protestantismo histórico como a Igreja Metodista e a Igreja Presbiteriana do Brasil.

${ }^{15}$ Os dois primeiros casos estão contemplados no Art. 128 do Código Penal brasileiro e o terceiro na Arguição de Descumprimento de Preceito Fundamental n. 54 do STF, de 2012.
} 
Marcos Feliciano, mas acompanharam o voto conservador dos outros evangélicos, principalmente da Assembleia de Deus (Gonçalves, 2016).

Marina Silva, também fiel da Assembleia de Deus, procura se colocar à distância dos temas religiosos por concorrer em eleições majoritárias. Assim como ocorreu com o candidato Garotinho na eleição presidencial de 2002, deu-se com Marina em 2010 e, principalmente, em 2014. Ambos passaram boa parte das campanhas fugindo da acusação de serem evangélicos fundamentalistas que ameaçam o Estado laico. Em todas as eleições majoritárias nas quais há evangélico participando a religião é tematizada. Esse é um enquadramento recorrente em todos os períodos eleitorais; ocorreu, por exemplo, em todas as campanhas eleitorais de Marcelo Crivella (PRB) para os Executivos estadual e municipal do Rio de Janeiro. Mas, em 2016, o grande feito de seu marketing foi construir uma distância simbólica da Igreja Universal do Reino de Deus, da qual é bispo licenciado e sobrinho do seu presidente-fundador, o bispo Macedo.

Mesmo assim, foi excessivo o tom quase apocalíptico da repercussão da vitória de Crivella à prefeitura do Rio de Janeiro, cuja expressão mais significativa eram falas segundo as quais, finalmente, a "Universal chegou ao poder". Sua eleição foi percebida para muitos como um passo importante para a expansão do fundamentalismo religioso no Brasil. O problema é a ameaça dos evangélicos ao Estado laico, e essa percepção é mais verdadeira quanto mais o catolicismo e a Igreja Católica estejam invisíveis na paisagem social brasileira. A conclusão foi que estávamos a caminho do obscurantismo que sobrepõe política $e$ religião, impondo-se como valor, comportamento e poder. ${ }^{16}$

\footnotetext{
${ }^{16}$ Mas, por outro lado, divulgou-se também a avaliação de que os evangélicos são bons para o desenvolvimento econômico do país, pois praticam uma ética empreendedora bastante afinada com a lógica da produção no capitalismo flexível. E, por fim, merece destaque a crítica à esquerda ou ao campo progressista sobre a necessidade de aprender a lidar com o segmento religioso evangélico.
} 
Em relação à complicada questão do aborto, Marina procura preservar-se politicamente propondo um plebiscito. No entanto, ela perde nos dois polos: os evangélicos a cobram por não se posicionar contra, enquanto o movimento feminista afirma que ela tem consciência de que o aborto não seria aprovado em uma consulta plebiscitária. Marina também se declara a favor da união civil entre pessoas do mesmo sexo, mas evita se referir à expressão casamento gay, por compreender casamento como um sacramento. Como comportamento geral, ela se esforça para manter sua religiosidade no foro privado, pois sabe que tal perfil lhe favorece em um segmento da população cada vez mais expressivo, mas que a excessiva identificação com ele a limita na disputa majoritária.

Em síntese, os evangélicos que têm seguido a trajetória eleitoral não são unívocos nos posicionamentos, mas de forma geral trabalham a favor das pautas moralizadoras. A diferença entre os posicionamentos está no quanto o Estado deve legislar sobre os comportamentos, o que faz da laicidade valor público assumido discursivamente por todos, mas com sentidos variados $e$ em disputa.

\section{Repressiva e punitiva}

A terceira linha de força refere-se a uma série de movimentações políticas, demandas coletivas, medidas governamentais que apontam para postura $e$ ações mais repressivas e punitivas dos aparelhos de segurança do Estado. A redução da maioridade penal, a lei do desarmamento, a lei antiterror, a política de encarceramento, a militarização de parcela da gestão pública, entre outros, são temas atuais cujo conjunto aponta para o aumento da violência do Estado sobre a população, sobretudo, os mais apartados do universo dos direitos.

Em boa medida, essa linha de força do sistema político tende a encontrar um considerável apoio popular, como as políticas de encarceramento $e$ ações mais repressivas da polícia na vigilância de "potenciais infratores". A demanda por segurança 
amplia a oferta de serviços privados, que não raro são prestados por agentes públicos. A crescente candidatura de Jair Bolsonaro do PSC (ligado à Assembleia de Deus Ministério Madureira) à Presidência da República é a principal, mas não única, expressão dessa linha de força. Se na dimensão da moralidade a categoria conservador se sobrepôs a fundamentalista, em relação às concepções políticas a categoria de acusação é fascista.

Após a votação do impeachment na Câmara dos Deputados, em 17 de abril de 2106, durante a qual fez um elogio ao torturador de Dilma Rousseff, Bolsonaro foi batizado pelo pastor Everaldo (candidato à Presidência da República em 2014 pelo PSC) no rio Jordão - o mesmo onde João Batista batizou Jesus. Jair Bolsonaro e Eduardo Cunha, assim como Garotinho, não são evangélicos que foram para a política, mas, o contrário, eles estenderam suas bases para esse universo religioso por meio de atos rituais e narrativas de conversão.

Boa parte dos que falam em nome dos evangélicos, entre eles o ex-presidente da Câmara dos Deputados, Eduardo Cunha, e o próprio presidente da Frente Evangélica, participa de um movimento mais amplo que trabalha a favor das restrições dos comportamentos e mesmo da criminalização da população. $\mathrm{O}$ projeto da redução da maioridade penal, aprovado pela Câmara, contou com forte condução e interferência de Cunha, que fez uma manobra regimental para refazer uma votação perdida. O projeto serviu como aglutinador de vários segmentos conservadores, dentre eles, a Frente Parlamentar Evangélica, que tem como presidente um delegado de polícia representante dos interesses tanto da corporação policial como da segurança privada.

Dogmaticamente, os evangélicos são contra a eutanásia e o aborto; na mesma linha são contra a pena de morte. Mas o pastor Marcos Feliciano e cerca de 1/3 da bancada evangélica votaram a favor da redução da maioridade penal. ${ }^{17}$ Não há justificação

${ }^{17} \mathrm{Cf}$.

http://www.camara.leg.br/internet/votacao/mostraVotacao.asp?ideVotacao $=6437$ $\underline{\text { \&numLegislatura }=55 \& \operatorname{cod} \text { Casa }=1 \& \text { numSessaoLegislativa }=1 \text { \&indTipoSessaoLe }}$ gislativa $=0 \&$ numSessao $=180 \&$ ind TipoSessao $=\mathrm{E} \&$ tipo $=$ partido 
teológica para aceitar ou refutar a redução da maioridade penal como há para condenar a pena de morte ou o aborto. Se o discurso evangélico pentecostal não justifica votar para diminuição da maioridade penal, ele também não se configura como um discurso religioso contrário como, por exemplo, o vinculado a setores religiosos progressistas em sintonia com o discurso dos direitos humanos.

Não é possivel afirmar que nessa linha de força a atuação parlamentar evangélica seja expressiva como a relativa à moralidade. Mas ela tem servido no mínimo como linha auxiliar dos interesses dos aparelhos de segurança pública (como as corporações policiais e militares) e privada (empresas).

\section{Socialmente intolerante}

Por fim, a última linha refere-se à qualidade e à intensidade das interações sociais em situações de forte antagonismo político. A crise política pela qual passa o país, pelo menos desde as manifestações de junho de $2013^{18}$, ocorre tanto no plano do sistema político como também desceu para as relações interpessoais da parcela da população mais mobilizada por tal crise. Na conjuntura atual, muitos brasileiros - pelo menos entre aqueles que acompanham com maior atenção à política nacional - têm experienciado, por um tempo prolongado, cisões entre opiniões e posições políticas e morais que têm tensionado alguns laços de amizade, de trabalho e familiares. Em especial, as redes sociais na internet potencializaram ainda mais as tensões interpessoais em torno de temas políticos e morais.

Vingança, fobia e ódio foram os termos mobilizados para descrever os afetos gerados pela "onda conservadora". Em 2015,

\footnotetext{
${ }^{18}$ Manifestações populares que tiveram início contra o aumento das tarifas de ônibus e foram se ampliando, por um lado, pelo território nacional e entre brasileiros no exterior e, por outro, em reivindicações. As consequências daquelas manifestações ainda necessitam de melhor compreensão, mas elas em boa medida foram uma espécie de gatilho da crise política que ainda está em curso no país.
} 
sobretudo, quando diversos conflitos interpessoais, seja por intolerância religiosa ou política, protagonizaram o debate público. $\mathrm{O}$ termo vingança foi evocado no debate em torno do projeto da redução da maioridade penal, cuja legitimidade baseou-se demasiadamente na temperatura da opinião pública. A fobia foi o outro afeto nomeado quando se tratou de diversidade sexual e a discriminação de gênero. A frase cristã mais recorrente é emblemática: "Amar o homossexual, mas ter repulsa ao homossexualismo". O discurso pentecostal traz limites à diversidade moral-comportamental. A homossexualidade é considerada como "degeneração moral" de homens e mulheres, por conseguinte, a união afetiva entre pessoas do mesmo sexo não pode constituir-se como família. Por fim, o ódio foi outro afeto evocado para descrever a conjuntura atual, seja por meio de atos de intolerância religiosa como no evento de forte repercussão pública quando uma pedra foi atirada na cabeça de uma menina praticante de uma religião afro-brasileira supostamente por pessoas evangélicas ${ }^{19}$, seja por meio de atos políticos como o feito contra o líder do MST, João Stédile, que sofreu um linchamento moral público quando foi perseguido e agredido verbalmente por um grupo organizado de manifestantes em uma saída de aeroporto. Em alguns momentos, a manifestação quase levou à violência física. ${ }^{20}$

Isso posto, é preciso ampliar o foco e entender tais atos como sintoma de afetos sociais mais amplos que são pouco abertos às diferenças, muito voltados sobre si como medida para a vida pública $e$, por vezes, agressivos simbólica e concretamente com o que negam, o que tem gerado atos de iconoclastia, de

\footnotetext{
${ }^{19}$ Esse é um desses casos-limite de intolerância, afinal, nada mais anti-bíblico do que um apedrejamento, que o diga a mulher adúltera, salva por Cristo com uma frase simples e de aplicação universal: "Atire a primeira pedra quem não tiver pecado".

${ }^{20}$ Cf. http://www1.folha.uol.com.br/poder/2015/09/1685372-lider-do-mst-ehostilizado-no-aeroporto-de-fortaleza.shtml
} 
vilipêndios por meio de rituais, de constrangimento moral $e$, apesar de menos frequente, mas não ausente, de violência física. ${ }^{21}$

Boa parte do pensamento social sobre o Brasil ancorou-se em conceitos como o de cordialidade, mesmo com sua violência não explícita (Holanda, 2006); de sincretismo que definiu a relação entre as religiões afro-brasileiras e o catolicismo (Bastide, 1971); ou de acomodação, que pautou o debate sobre a entrada do pentecostalismo ao país (Willems, 1967). De certa forma, os diferentes conceitos pressupõem ajustes, negociações, arranjos, em síntese, mediações. No entanto, os termos guerra $e$ intolerância têm sido a tônica de algumas relações inter-religiosas e de confronto de posições política no Brasil contemporâneo.

\section{Consideração final}

A configuração acima é uma visada da conjuntura atual, que tem sido nominada como "onda conservadora". A religião, as religiões, os religiosos fazem parte desse movimento mais amplo, sendo constituintes e constituídos por ele. Desse modo, tratei aqui os evangélicos não sendo causa e nem resultante, mas como estão articulados ao processo social mais geral. Assim como nem todos os evangélicos são conservadores, a pauta conservadora vai além da pauta dos evangélicos conservadores. Dela participam também católicos, outras religiões e não religiosos.

O que se configura como a chamada "onda" é, portanto, um emaranhado de vários jogadores em diferentes tabuleiros. Daí pensá-la quebrada em linhas de força que resultam dos processos sociais, e que por sua definição são desiguais, assimétricos e com temporalidades distintas. Trata-se de vetores sociais das mudanças porque passa o país. Não se pretende atribuir a qualquer uma delas o fator causal para a crise em curso, mas analisar como se articulam e configuram a conjuntura atual. Elas estabelecem entre

\footnotetext{
${ }^{21}$ Relatório sobre intolerância e violência religiosa no Brasil (2011-2015): resultados preliminares. Ministério Mulheres, da Igualdade Racial, da Juventude, Direitos Humanos; organização Alexandre Brasil Fonseca, Clara Jane Adad Brasília: Secretaria Especial de Direitos Humanos, SDH/PR, 2016.
} 
si conexões parciais, ora por afinidades ora por estratégia, mas todas convergem no sentido da praia.

\section{Referências bibliográficas}

Alencar, Gedeon F. Matriz Pentecostal Brasileira: Assembleias de Deus (1911-2011), Rio de Janeiro, Novos Diálogos, 2013.

AlmEIDA, Ronaldo de. Dez anos do "chute na santa: a intolerância com a diferença. In: SILVA, Vagner Gonçalves da (org.). Intolerância religiosa: impactos do neopentecostalismo no campo religioso afrobrasileiro. São Paulo, Edusp, 2007, pp.171-189. 2009.

A Igreja Universal e seus demônios. São Paulo, Terceiro Nome,

. "A visita de Francisco e a abertura do compasso" In: Le Monde Diplomatique Brasil, São Paulo, out, 2013.

BASTIDE, Roger. Religiões Africanas no Brasil: contribuição a uma sociologia das interpenetrações de civilizações. São Paulo, Livraria Pioneira Editora, vol. I e II, 1971.

BUTLER, Judith. O não pensamento em nome do não normativo. In: Quadros de guerra: quando a vida é passível de luto?, Rio de Janeiro, Civilização Brasileira, 2015, pp.197-232.

CASANOva, José. Public Religious in the Modern World, Chicago e London, University of Chicago Press, 1994.

CORREA, Marina. A operação do carisma e o exercício do poder: a lógica dos missionários das igrejas Assembleias de Deus no Brasil. Tese (Doutorado em Ciência da Religião), PUC/SP, São Paulo, 2012.

FERNANDES, R., et alii. Novo Nascimento: os evangélicos em casa, na política e na igreja. Rio de Janeiro, Mauad, 1998.

FONSECA, Alexandre B. Religion and democracy in Brazil: a study of the leading evangelical politicians. In: FRESTON, Paul (org.). Evangelical Christianity and Democracy in Latin America. Oxford, Oxford University Press, vol. 1, 2008, pp.163-206.

FRESTON, Paul. Breve história da Assembleia de Deus. Religião e Sociedade, Rio de Janeiro, vol. 16, nº 3, 1994, pp.104-129. 
. Evangelicals and Politics in Asia, Africa and Latin America. Cambridge, Cambridge University Press, 2004.

GONÇALVES, Rafael Bruno. O discurso religioso na política e a política no discurso religioso: uma análise da atuação da Frente Parlamentar Evangélica na Câmara dos Deputados (2003-2014). Tese (Doutorado em Sociologia), IESP, Rio de Janeiro, 2016.

GUTIERREZ, Carlos. Reflexividade evangélica a partir da produção crítica e construção de projetos de vida na Igreja Universal do reino de Deus. Tese (Doutorado em Antropologia Social), Unicamp, Cmapinas, 2017.

HolandA, Sérgio Buarque. Raízes do Brasil, São Paulo, Companhia da Letras, 2006.

LIMONGI, Fernando. O passaporte de Cunha e o Impeachment: a crônica de uma tragédia anunciada. Novos Estudos, vol. 103, São Paulo, Cebrap, 2015, p.99-112.

MACHADO, Maria das Dores C. Política e Religião: A participação dos evangélicos nas eleições. Rio de Janeiro, Fundação Getúlio Vargas, 2006. v. 1.

MAFRA, Clara. Os Evangélicos. Rio de Janeiro, Jorge Zahar, 2001.

MARIANO, Ricardo. Expansão e ativismo político de grupos evangélicos conservadores Secularização e pluralismo em debate. Civitas: Revista de Ciências Sociais, vol. 16, 2016, pp.710-728.

ORO, Ari Pedro; Alves, D. Renovação Carismática Católica e Pentecostalismo Evangélico: convergências e divergências. Debates do NER, vol. 30, Porto Alegre, UFRGS, 2016, pp.219-245.

. As bases da nova direita. Novos Estudos n¹9, CEBRAP, São Paulo, 1987, pp.26-45.

TrOeltSCH, Ernest. Igreja e seitas. Religião \& Sociedade, vol. 14, $\mathrm{n}^{\circ} 3$, Rio de Janeiro, Iser, 1987, 134-144.

WILlENS, Emilio. Followers of the New Faith: Culture Change and the Rise of Protestantism in Brazil and Chile. Vanderbilt University Press, 1967. 